\section{AB1314-HPR ECONOMIC EVALUATION OF THE DR. BART APP IN PEOPLE WITH KNEE AND/OR HIP OSTEOARTHRITIS}

T. Pelle ${ }^{1,2}$, K. Bevers ${ }^{1}$, F. Van den Hoogen ${ }^{1,2}$, J. Van der Palen ${ }^{3}$, C. Van den Ende ${ }^{1,2} .{ }^{1}$ Sint Maartenskliniek, Nijmegen, Netherlands; ${ }^{2}$ Radboudumc, Nijmegen, Netherlands; ${ }^{3}$ University of Twente, Enschede, Netherlands

Background: Self-management is of paramount importance in non-surgical treatment of knee and/or hip osteoarthritis (OA). Modern technologies offer the possibility to support self-management $24 / 7$. We developed an e-self-management application (dr. Bart app) for people with knee and/or hip OA ${ }^{1}$.

Objectives: To evaluate the (incremental) cost-utility and cost-effectiveness of the dr. Bart app compared to usual care in people with knee/hip OA, applying a health care perspective.

Methods: This economic evaluation was conducted alongside a 6-month randomized controlled trial, in which 214 participants were offered to use the dr. Bart app for 6 months and 213 participants received care as usual. Health care costs were measured using self-reported questionnaires. Clinical outcome measures were quality-adjusted life years (QALYs) according to the EuroQol (EQ-5D-3L), the EuroQol rating scale (QALY-TRS), and the five subscales of KOOS/HOOS. Cost and effect differences were estimated using longitudinal linear mixed models and cost-effectiveness acceptability curves. Bootstrapping was used to estimate statistical uncertainty. Results: Mean age of participants was 62.1 (SD 7.3) years, with the majority being female (72\%) (Table 1). The difference in health care costs was non-significantly in favour of the intervention group ( $€-31.12(95 \% \mathrm{Cl}:-66 ; 3))$. Table 2 shows estimated treatment effects over 6 months. We found small but positive effects on symptoms, pain and activities of daily living (ADL) in favour of the dr. Bart app group. For QALY and QALY-TRS, the probability of the dr. Bart app being cost-effective compared to usual care was 0.80 and 0.60 at a willingness to pay (WTP) of $€ 10.000$ and 0.72 and 0.44 at WTP $€ 80.000$, respectively. For symptoms, pain and ADL, the probability that dr. Bart app was cost-effective was $>82 \%$ and for activities and quality of life $<40 \%$, regardless of WTPs.

Table 1. Baseline characteristics.

\begin{tabular}{lcc}
\hline & Dr. Bart app group $(\mathrm{n}=\mathbf{2 1 4})$ & Control group $(\mathrm{n}=\mathbf{2 1 3})$ \\
\hline Age, years; mean (SD) & $62.1(7.7)$ & $62.1(7.0)$ \\
Female, $\mathrm{n}(\%)$ & $147(68.7)$ & $159(74.7)$ \\
BMI, kg/m $\mathbf{m}^{2}$ mean (SD) & $27.8(5.1)$ & $27.3(4.8)$ \\
Main OA-location, knee; $\mathbf{n ( \% )}$ & $157(73.4)$ & $156(73.2)$ \\
\hline
\end{tabular}

Conclusion: This economic evaluation, from a health care perspective, showed that costs were not significantly lower for the dr. Bart app group compared to usual care. Given the non-invasive character of the intervention and the moderate probability to be cost-effective for the majority of outcomes, the dr. Bart app has only the potential to serve as a trustworthy tool to provide education and goal setting regarding $O A$ and its treatment options.

Table 2. Estimated treatment effects over 6 months.

\begin{tabular}{lccc}
\hline & $\begin{array}{c}\text { Estimated difference over } \mathbf{6} \text { months } \\
\text { between groups } \mathbf{( 9 5 \% ~ C l )}\end{array}$ & $\begin{array}{c}\text { WTP } \\
€ 10,000\end{array}$ & $\begin{array}{c}\text { WTP } \\
€ 80,000\end{array}$ \\
\hline Health care costs, $€$ & $-31(-66 ; 3)$ & $\mathrm{N} / \mathrm{A}$ & $\mathrm{N} / \mathrm{A}$ \\
QALY & $0.0045(-0.0119 ; 0.0210)$ & 0.80 & 0.72 \\
QALY-TRS & $-0.0015(-0.0149 ; 0.0111)$ & 0.60 & 0.44 \\
KOOS/HOOS & $2.6(-0.8 ; 5.8)$ & 0.93 & 0.93 \\
- Symptoms & $3.0(-0.2 ; 6.1)$ & 0.97 & 0.97 \\
- Pain & $1.9(2.3 ; 6.1)$ & 0.82 & 0.82 \\
- ADL & $-0.7(-5.1 ; 3.8)$ & 0.37 & 0.37 \\
- Activities & $-0.7(-4.8 ; 3.2)$ & 0.36 & 0.36 \\
- Quality of life & & &
\end{tabular}

${ }^{*}$ Control group serving as reference category. Abbreviations: KOOS; Knee Injury and Osteoarthritis Outcome Score; HOOS; Hip Disability and Osteoarthritis Outcome Score.

\section{References:}

[1] Pelle T, Bevers K, van der Palen J, van den Hoogen FHJ, van den Ende $\mathrm{CHM}$. Development and evaluation of a tailored e-self-management intervention (dr. Bart app) for knee and/or hip osteoarthritis: study protocol. BMC Musculoskelet Disord [Internet]. 2019 Dec 31;20(1):398.

Disclosure of Interests: None declared

DOI: 10.1136/annrheumdis-2020-eular.1721

\section{AB1315-HPR HYPERBARIC OXYGEN THERAPY IN FIBROMYALGIA PATIENTS - DOUBLE-BLIND PROSPECTIVE CLINICAL TRIAL}

B. Raffeiner ${ }^{1}$, F. Ometto ${ }^{2,3}$, D. Astorri ${ }^{3}$, C. Botsios ${ }^{3}$, G. Pulga ${ }^{4} .{ }^{1}$ Bolzano Hospital, Medicine Department, Bolzano, Italy; ${ }^{2}$ Local Health Unit 1 , Medicine
Department, Belluno, Italy; ${ }^{3}$ University of Padova, System's Department, Padova, Italy; ${ }^{4}$ Bolzano Hospital, Hyperbaric Unit, Bolzano, Italy

Background: Hyperbaric Oxygen Therapy (HOT) proved effective in improving of symptoms of patients affected by fibromyalgia syndrome (FMS) [1].

Objectives: The objective of the present study was to evaluate the effectiveness of HOT compared to hyperbaric treatment with no oxygen therapy (PBO) in the symptoms and working ability in FMS.

Methods: We conducted a prospective trial in employed patients with FMS, randomly assigned to HOT or PBO. Patients and evaluating clinicians were blinded to the treatment. HOT arm comprised 40 sessions, 5 days/week, 120 minutes, $100 \%$ oxygen at 2ATA; PBO comprised the same sessions without oxygen. Evaluations were at baseline, after 4 (T1) and 8 weeks (T2). Parameters considered were: socio-demographics, biochemistry, clinical evaluation and patient-reported outcomes (PROs). Baseline assessment included questions BELIEF (how much do you hope to improve with this treatment) and HOPE (how much do you expect to improve with this treatment), with VAS response. Spearman's, Mann-Whitney's, Kruskal-Wallis and Fisher's Exact test were used.

Results: 12 patients were included and completed the study, 6 in each arm (Tab. 1). No significant difference was observed in clinical measures or PROs at T1 and T2 between HOT and PBO arms, except for Working Productivity and Activity Impairment Questionnaire (WPAI) (result III) (Tab. 2). In both arms disease duration was associated with worse PROs (Widespread pain index $r=0.59, p=0.037$, Severity Score $r=0.81, p=0.025$ ); higher $B M I$ with improvement in function at T2 $(r=0.63, p=0.027)$; higher baseline scores in BELIEF with reduction symptoms number $(r=-0.67, p=0.021)$, higher scores in HOPE with reduction in Health Assessment Questionnaire $(r=-0.057, p=0.039)$

Table 1. Patients characteristics

\begin{tabular}{cccc}
\hline & All & HOT & PBO \\
\hline Number & 12 & 6 & 6 \\
Age* $^{*}$ & $55,5(44 ; 59,75)$ & $55,5(47,75 ; 60)$ & $51(41 ; 58,75)$ \\
Females $^{* *}$ & $6(100)$ & $6(100)$ & $6(100)$ \\
Disease duration $^{*}$ & $10(8,25 ; 26,75)$ & $9,5(7,5 ; 20,75)$ & $15(10 ; 26,75)$ \\
BMl $^{*}$ & $25,5(22,25 ; 31)$ & $25(22,75 ; 28)$ & $28,5(23 ; 31,75)$ \\
Smoke $^{* *}$ & $0,5(0 ; 1)$ & $0(0 ; 1)$ & $1(0,25 ; 1)$ \\
HOPE score* $^{*}$ & $0(0 ; 1)$ & $0,5(0 ; 1)$ & $0(0 ; 0)$ \\
>=80** & $9(64,3)$ & $5(62,5)$ & $4(66,7)$ \\
BELIEF score* & $70(60 ; 80)$ & $75(67,5 ; 83,75)$ & $62,5(60 ; 68,75)$ \\
$>==70^{* *}$ & $8(57,1)$ & $6(75)$ & $2(33,3)$ \\
\hline
\end{tabular}

*median (IQR); ** number (\%)

Table 2. Change from baseline in clinical measures and PROs at T2.

\begin{tabular}{|c|c|c|c|c|c|c|c|c|}
\hline & \multicolumn{3}{|c|}{ Medians (IQR) } & \multirow[t]{2}{*}{$\begin{array}{c}\mathbf{P} \\
\text { value }\end{array}$} & \multicolumn{3}{|c|}{$\begin{array}{c}\geqq 20 \text { Percentage } \\
\text { amelioration No. } \\
(\%)\end{array}$} & \multirow[t]{2}{*}{$P$ value } \\
\hline & All & нот & PBO & & All & НОт & PBO & \\
\hline $\begin{array}{l}\text { Short Form-36 } \\
\text { - Physical }\end{array}$ & $1(-1 ; 4)$ & $3(-1 ; 5,5)$ & $0,5(-0,75 ; 3,25)$ & ns & $0(0)$ & $0(0)$ & $0(0)$ & ns \\
\hline SF-36 - Mental & $4(-1 ; 8)$ & $6(2,5 ; 9,5)$ & $1(-1,75 ; 5,25)$ & ns & $0(0)$ & $0(0)$ & $0(0)$ & ns \\
\hline $\begin{array}{l}\text { Severity score } \\
\text { - total }\end{array}$ & $-13(-15 ;-2)$ & $\begin{array}{c}-15 \\
(-17 ;-13,5)\end{array}$ & $-3(-5,5 ;-0,5)$ & ns & $2(18,2)$ & $2(40)$ & $0(0)$ & ns \\
\hline Number symptoms & $-3(-4 ; 0)$ & $\begin{array}{c}-4 \\
(-4,5 ;-1,5)\end{array}$ & $-2(-3 ;-0,25)$ & ns & $2(18,2)$ & $2(40)$ & $0(0)$ & ns \\
\hline SASP score & $-1(-3 ; 0)$ & $\begin{array}{c}-2 \\
(-3,5 ;-0,5)\end{array}$ & $-1(-1,75 ;-0,25)$ & ns & $1(9,1)$ & $0(0)$ & $\begin{array}{c}1 \\
(16,7)\end{array}$ & ns \\
\hline $\begin{array}{l}\text { Widespread pain } \\
\text { index }\end{array}$ & $0(-2 ; 0)$ & $0(-2 ; 0)$ & $-0,5(-1,75 ; 0)$ & ns & $2(18,2)$ & $2(40)$ & $0(0)$ & ns \\
\hline Tender Points & $-2(-3 ;-0,5)$ & $-2(-3,5 ;-1)$ & $-1,25(-2 ;-0,13)$ & ns & $3(27,3)$ & $2(40)$ & 1 & Ns \\
\hline $\begin{array}{l}\text { Count }(0-18 \\
\text { Health Assessment } \\
\text { Questionnaire }\end{array}$ & t $0(0 ; 0)$ & $\begin{array}{c}0 \\
(-0,5 \div 0,5)\end{array}$ & $0(0 ; 0)$ & ns & $3(27,3)$ & $1(20)$ & $\begin{array}{c}(16,7) \\
2 \\
(33,3)\end{array}$ & ns \\
\hline $\begin{array}{l}\text { Questionnaire } \\
\text { Fibromyalgia } \\
\text { Impact } \\
\text { Questionnaire }\end{array}$ & $10(0 ; 15)$ & $\begin{array}{l}(-0,5,0,5) \\
10(7,5 ; 15)\end{array}$ & $2,5(-3,75 ; 12,5)$ & ns & $1(9,1)$ & $0(0)$ & $\begin{array}{c}1 \\
(16,7)\end{array}$ & ns \\
\hline WPAI result-2 & $\begin{array}{c}-0,5 \\
(-1,25 ;-0,13)\end{array}$ & $\begin{array}{c}-1,5 \\
(-2 ;-0,5)\end{array}$ & $\begin{array}{c}-0,25 \\
(-0,5 ; 0,19)\end{array}$ & ns & $3(21,4)$ & $0(0)$ & $\begin{array}{c}3 \\
(37,5)\end{array}$ & ns \\
\hline WPAI result-3 & $0(-2,38 ; 0)$ & $\begin{array}{c}-2,75 \\
(-3,88 ;-2)\end{array}$ & $0(0 ; 0)$ & ns & $5(35,7)$ & $0(0)$ & $\begin{array}{c}5 \\
(62,5)\end{array}$ & $P=0.008$ \\
\hline WPAI result-1 & $\begin{array}{c}-1(-3,25 ;- \\
0,38)\end{array}$ & $\begin{array}{c}-3,5 \\
(-4,75 ;-1,5)\end{array}$ & $-0,5(-1 ; 0,38)$ & ns & $6(42,9)$ & $\begin{array}{c}2 \\
(33,3)\end{array}$ & $4(50)$ & ns \\
\hline
\end{tabular}

Conclusion: 8-week HOT treatment does not substantially improve symptoms in FMS compared to PBO. All patients on hyperbaric treatment may experience amelioration of symptoms: other factors should be considered, including beliefs and expectations on the treatment. 
References:

[1] DOI:10.1371/journal.pone.0127012

Disclosure of Interests: None declared

DOI: 10.1136/annrheumdis-2020-eular.5927

\section{AB1316-HPR COMORBIDITIES IMPACT ON PHYSICAL REHABILITATION PROGRAM OUTCOMES IN PATIENTS WITH KNEE OSTEOARTHRITIS}

V. Salaru' ${ }^{1}$, A. Vizdoaga ${ }^{2}$, L. Mazur-Nicorici ${ }^{3}$, M. Cebanu ${ }^{4}$, T. Rotaru ${ }^{5}$, S. Vetrila ${ }^{3}$, M. Garabajiu ${ }^{3}$, N. Loghin-Oprea ${ }^{3}$, V. Sadovici-Bobeica ${ }^{3}$, M. Mazur $^{3} .{ }^{1}$ State University of Medicine and Pharmacy "Nicolae Testemitanu", Family Medicine, Chișinău, Moldova, Republic of; ${ }^{2}$ University Medical Rehabilitation Center, Medical Rehabilitation, Physical and Manual Therapy, Chișinău, Moldova, Republic of; ${ }^{3}$ State University of Medicine and Pharmacy "Nicolae Testemitanu", Internal Medicine, Chișinău, Moldova, Republic of; ${ }^{4}$ State University of Medicine and Pharmacy "Nicolae Testemitanu", Emergency Medicine, Chișinău, Moldova, Republic of; ${ }^{5}$ Institute of Cardiology, Chișinău, Moldova, Republic of

Background: Physical rehabilitation is proposed as a method of non-pharmacological treatment of knee osteoarthritis $(\mathrm{OA})$ by the EULAR and OARSI recommendations. At the same time, presence of concomitant diseases could influence the condition of patients and the outcomes of the rehabilitation program.

Objectives: To evaluate the frequency of comorbidities in OA patients and to appreciate their impact on outcomes of the physical rehabilitation program.

Methods: A prospective control case study was conducted in the University Rehabilitation Center. The patients underwent clinical examination, VAS scale was used to assess level of pain, and Knee Injury and Osteoarthritis Outcome Score (KOOS) with 5 domains (Pain, Symptoms, ADL, Sport, QoL) for joint function assessment. These parameters were evaluated at the onset of the program (T0) and at the end of the 10th day (T1). Medical data records, general clinical exam and Charlson Comorbidities Index $(\mathrm{CCl})$ assessed the comorbidities.

Results: 48 patients with OA were included in the study, 37 patients of them were found with comorbidities. The most frequent associated diseases were: cardiovascular- $76.6 \%$, obesity- $59.9 \%$, and endocrine - $12.9 \%$ cases. At T0, significantly lower levels in the group with comorbidities were identified on the domains Pain, Sport and QoL. The CCl in patients with comorbidities was $3.29 \pm 0.14$ points $(82.1 \%$ for 1 -year survival rate). At the T1 moment, we found an improvement in joint functionality in both groups. The mean value of the VAS score group of patients without comorbidities decreased from $48,18 \mathrm{~mm}$ to $21,36 \mathrm{~mm}$ $(p<0.05)$ and for the group of patients with comorbidities $-64,2$ at $/ 36,2 \mathrm{~mm}$ $(p<0.001)$. Significant improvement in joint function in the comorbidities group was in Pain $(p<0.01)$, Sport $(p<0.05)$ and Qol $(p<0.01)$ domains, at the same in patients without comorbidities, the improvement was significant in all 5 domains. Conclusion: Comorbidities are highly associated to knee osteoarthritis and prove to have a negative influence on the results of the physical rehabilitation program; therefore, we would recommend to apply individualized rehabilitation programs adapted to the associated conditions of each patient.

Disclosure of Interests: None declared

DOI: 10.1136/annrheumdis-2020-eular.2725

\section{AB1317-HPR YOGA-THERAPY: IMPROVEMENT IN PSORIATIC ARTHRITIS PROMS AT 4 MONTHS}

C. B. Colaco ${ }^{1}$, V. Sadana ${ }^{2}$, K. Anie ${ }^{2} .{ }^{1}$ LNWUH NHS Trust, CMH Rheumatology Unit, London, United Kingdom; ${ }^{2}$ LNWUH NHS Trust, CMH Rheumatology Unit, London, United Kingdom

Background: Psoriatic Arthritis and Psoriasis have a major impact on QOL with associated mood disorders and Cardiovascular disease and Cancer as inter-related co-morbidities ${ }^{1}$. Yoga therapy ( $\left.\mathrm{Y}-\mathrm{T}\right)$ has been used in several Long Term Conditions ${ }^{2}$ and we have reported Rapid improvement in Proms in RA (RCP 2018) and so compared results of a PsA cohort offered the same Y-T intervention. Objectives: This first in UK PsA study investigated: a) impact of a 16 week Y-T intervention on functional outcomes and QOL in 10 PsA patients, b) acceptability and experiences of the intervention. We present results in comparison to a previously reported RA cohort $n=10$.

Methods: Ten adult PsA patients (2 M 8 F Age 32-67 Avg: 53.7 Y; PsA diagnosis: $6.45 \mathrm{yrs:} 1$ Juvenile onset) consented to 10 individual Y-T sessions (weekly $\times$ 4; biweekly $\times 6$ ) with a yoga therapist in a standard consulting room. The intervention was tailored to the needs and abilities of each patient and included: breath-centered physical yoga postures, breathing and visualization techniques, mantras and meditation, with supportive Lifestyle/behavioural strategies. All participants completed measures pre- and post-intervention (EQ-5D HAQ HADS $P G I C)$ to assess change in health status.

Results: A 10 session course of $\mathrm{Y}$-T over 16 weeks was completed with 92/100 PsA YT sessions. Note 1 patient had unrelated Trauma and withdrew after 2 sessions. This confirms acceptability of delivery in a clinic setting and all participants reported strong adherence to practices (0-1) and strong belief (0-2) in impact of yoga. (Likert 5 point 0-4 scale).

Further data on only 9 PsA participants will be presented in comparison to the previous RA cohort of 10 .

PsA patients n=9: Pain reduced $25 \%$ HADs Depression reduced 39\% Anxiety reduced $25 \%$

$\mathrm{HAQ}$ health score improvement was significant at $\mathrm{P}<0.04$ (ANOVA).

EQol $5 \mathrm{~d}(3 \mathrm{~L})$ improved $24 \%$ but overall $\mathrm{QOL}$ remained below $50 \%$ max calculated TTO.

RA patients had recorded stable overall TTO at a higher level 0.63 pre and post Y-T.

PGIC record of positive change is recorded as a reduction on VAS from $5 / 5$ to $2.4 / 5$

We will add 12 month FU data set in PsA to compare with 24 month data in the RA cohort.

Conclusion: Yoga-Therapy is deliverable and acceptable in a NHS clinic setting for PsA. Improved PROMS begs further larger studies of mechanisms of bio-psychosocial intervention in long term inflammatory conditions. The outcomes support the Poly Vagal Theory ${ }^{3}$ as an effector model, via the bio-mechanistic neuro-inflammatory reflex ${ }^{4}$. We propose further Health Economic analysis of this $2500 \mathrm{yr}$ old Yoga model for long term conditions to examine any long term cost benefit to the NHS.

References:

[1] Coates LC et al Rheumatology 2018;57:1321-1331 Remission in psoriatic arthritis-where are we now?

[2] Khalsa, SB, Cohen, L, McCall, T \& Telles, S (2016) (Eds). The Principles and Practice of Yoga in Health Care. Handspring Publishing.

[3] Sullivan M B Porges SW et alFront. Hum. Neurosci., 2018 Yoga Therapy and Polyvagal Theory: The Convergence of Traditional Wisdom and Contemporary Neuroscience for Self-Regulation and Resilience

[4] Pavlov V Tracey K Nat Rev Endocrinol. 2012 Dec; 8(12): 743-754. The vagus nerve and the inflammatory reflex-linking immunity and metabolism

Table 1. PsA vs RA post Yoga Therapy PROMs at $4 \mathrm{mth}$.

PsA $n=9$ PsA 4 mPsA 4 m \%RA $n=10$ PreRA4m FU RA $4 m \%$ pre

HADS m Depression

HADS m Anxiety

Mean HAQ

Mean $\mathrm{HAQ}$
$M$ Pain Score (HAQ)

$M$ Health Score (HAQ)

$\mathrm{M}$ H Utility TTO (EQol5d)

PGIC

\begin{tabular}{|c|c|c|c|c|c|}
\hline 6.33 & 3.88 & -39 & 6.7 & 2.3 & -65 \\
\hline 8.56 & 6.44 & -25 & 9.4 & 4.8 & -48 \\
\hline .79 & 0.75 & -2 & 0.78 & 0.48 & -26 \\
\hline 60 & 45.00 & -25 & 57 & 24 & -58 \\
\hline 60 & 42.7 & $-29 p<0.04$ & 51 & 17.2 & -66 \\
\hline 0.41 & 0.5 & +24 & 0.63 & 0.63 & 0 \\
\hline
\end{tabular}

Acknowledgments: CMH Rheumatology Support Group

Disclosure of Interests: C Bernard Colaco Grant/research support from: Trave Support for Conference attendance, Speakers bureau: Menarini, Vidhi Sadana: None declared, Kofi Anie: None declared

DOI: 10.1136/annrheumdis-2020-eular.5968

\section{AB1318-HPR VAGUS NERVE STIMULATION IN PATIENTS WITH RHEUMATOID ARTHRITIS: 48 MONTH SAFETY AND EFFICACY}

F. Koopman ${ }^{1}$, A. Musters ${ }^{2}$, M. Backer ${ }^{2}$, D. Gerlag ${ }^{2}$, S. Miljko ${ }^{3}$, S. Grazio ${ }^{4}$, S. Sokolovic ${ }^{5}$, Y. Levine ${ }^{6}$, E. Glass ${ }^{6}$, D. Chernoff ${ }^{6}$, N. De Vries ${ }^{2}$, P. P. Tak ${ }^{2}$. ${ }^{1}$ Academic Medical Center/University of Amsterdam, Amsterdam, Netherlands; ${ }^{2}$ University of Amsterdam, Amsterdam, Netherlands; ${ }^{3}$ University Clinical Hospital, Mostar, Bosnia and Herzegovina; ${ }^{4}$ Clinical Hospital Center Sestre Milosrdnice, Zagreb, Croatia; ${ }^{5}$ Sarajevo University Clinical Center, Sarajevo, Bosnia and Herzegovina; ${ }^{6}$ SetPoint Medical, Valencia, United States of America

Background: Rheumatoid arthritis (RA) is a disease with significant remaining unmet medical needs for better treatments. Vagus nerve stimulation (VNS) to activate the inflammatory reflex (cholinergic anti-inflammatory pathway) represents a novel experimental therapy for RA. ${ }^{1}$ Previously, we reported that inflammatory reflex activation by VNS reduced pro-inflammatory cytokine production and improved disease activity in a 17-patient rheumatoid arthritis (RA) proof-ofconcept study using a reprogrammed epilepsy stimulator2; clinical improvement was sustained for 24 months without untoward safety signals. ${ }^{3}$ Here we report the 48 months results from this long-term observational study.

Objectives: Determine the long-term safety and efficacy of VNS for the treatment of RA

Methods: In the primary study, a VNS device was implanted into 17 RA patients, mostly with insufficient response to multiple conventional and biologic DMARDs on stable background of methotrexate ( $\leq 25 \mathrm{mg}$ weekly) therapy ${ }^{2}$. The device electrically stimulated the vagus nerve, $1-4 \mathrm{~min} /$ day, over a 12 -week open label 